\title{
Apple Sauce Improves Detection of Esophageal Motor Dysfunction During High-Resolution Manometry Evaluation of Dysphagia
}

\author{
Benjamin Basseri • Mark Pimentel • \\ Omid A. Shaye $\cdot$ Kimberly Low $\cdot$ \\ Edy E. Soffer · Jeffrey L. Conklin
}

Received: 7 June 2010/Accepted: 22 November 2010/Published online: 23 December 2010

(c) The Author(s) 2010. This article is published with open access at Springerlink.com

\begin{abstract}
Background Esophageal manometry utilizes water swallows to evaluate esophageal motor abnormalities in patients with dysphagia, chest pain, or reflux symptoms. Although manometry is the gold standard for evaluation of these symptoms, patients with dysphagia often have normal results in manometry studies.

Aim The objective of this work was to test the hypothesis that challenging the esophagus with viscous apple sauce boluses uncovers motor abnormalities in patients with dysphagia not seen when using water swallows.

Methods High-resolution esophageal manometry was performed using ten water swallows followed by ten apple sauce swallows in consecutive subjects presenting with dysphagia. Subjects with grossly abnormal water swallow evaluations were excluded. Each swallow was categorized as normal, hypotensive (distal isobaric contour plots of $<30 \mathrm{mmHg}$ over $>5 \mathrm{~cm}$ ), or simultaneous (distal
\end{abstract}

\footnotetext{
B. Basseri - M. Pimentel - O. A. Shaye $\cdot$ K. Low ·

E. E. Soffer · J. L. Conklin $(\bowtie)$

GI Motility Program, Division of Gastroenterology,

Cedars-Sinai Medical Center, 8730 Alden Drive, Suite 225E,

Los Angeles, CA 90048, USA

e-mail: Jeffrey.Conklin@cshs.org

B. Basseri

e-mail: Benjamin.Basseri@cshs.org

M. Pimentel

e-mail: Mark.Pimentel@cshs.org

O. A. Shaye

e-mail: Omid.Shaye@cshs.org

K. Low

e-mail: Kimberly.Low@cshs.org

E. E. Soffer

e-mail: Edy.Soffer@cshs.org
}

esophageal velocity $\geq 8.0 \mathrm{~cm} / \mathrm{s}$ ). Ineffective esophageal motility (IEM) was defined as $\geq 30 \%$ hypotensive swallows, and pressurization was defined as $\geq 20 \%$ simultaneous pressure waves.

Results Data from 41 subjects was evaluated. Overall, $96.3 \%$ of water swallows were normal, $2.9 \%$ hypotensive, and $0.7 \%$ simultaneous. Only $70.3 \%$ of viscous swallows were normal; $16.7 \%$ were hypotensive and $13.0 \%$ were simultaneous $(P<0.001$ all groups). Seven $(17.1 \%)$ met criteria for IEM, and pressurization with viscous swallows was observed for nine $(22.0 \%)$. Fourteen subjects $(34.1 \%)$ had abnormal results from viscous studies. The presence of any abnormal water swallows was predictive of abnormal viscous swallows $(\mathrm{OR}=9.00, \mathrm{CI}=2.15-80.0)$, although the presence of hypotensive or simultaneous water swallows was not associated with IEM $(\mathrm{OR}=0.63, \mathrm{CI}=0.16-2.17)$ or pressurization $(\mathrm{OR}=7.00, \mathrm{CI}=0.90-315.4)$ with viscous apple sauce.

Conclusions Apple sauce challenge increased identification of classifiable motor disorders in patients with dysphagia and may be preferred to alternative bolus materials.

Keywords Apple sauce - Dysphagia - Esophagus · High-resolution manometry $\cdot$ Motility

\section{Introduction}

Esophageal manometry is the gold standard for evaluating patients referred for investigation of dysphagia or noncardiac chest pain when endoscopy, barium radiology, or both, identify no causative anatomical or mucosal abnormalities. These studies may be unremarkable or suggest a motor disorder, for example achalasia or diffuse esophageal spasm (DES), which can be diagnosed definitively by 
esophageal manometry. Other indications for esophageal manometry include evaluation of esophageal motor function before fundoplication surgery, and location of the lower esophageal sphincter (LES) to guide $\mathrm{pH}$ probe placement [1].

Traditional esophageal manometry catheters are typically configured with 5-8 water-perfused side holes or solid-state pressure sensors spaced at $3-5 \mathrm{~cm}$ intervals along the catheter. A major disadvantage of traditional manometry is that it gives an incomplete picture of esophageal motor function because sensors are widely spaced, usually sense in only one direction around the catheter circumference, and do not enable simultaneous recording from the entire esophagus. Newly developed high-resolution manometry systems use catheters that have 36 circumferentially sensitive, solid-state, pressure sensors spaced at $1-\mathrm{cm}$ intervals along the catheter. This gives the catheter a recording segment of $35 \mathrm{~cm}$. When appropriately positioned, the pressure-sensing segment spans from the pharynx to the stomach, so pressure data are obtained simultaneously from the entire esophagus and its sphincters. Sophisticated software algorithms display pressure data as a color-encoded isocontour plot, rather than discontinuous line tracings stacked one above the other. This provides a much more spatially detailed picture of esophageal motor function that may increase the sensitivity of esophageal manometry in finding pathologic esophageal motor abnormalities [2].

The conventional procedure for performing esophageal manometry is to record changes in esophageal body and sphincter pressures produced by ten to twenty $5-10 \mathrm{ml}$ water swallows [3]. It is not entirely clear whether conventional esophageal manometry with water swallows accurately portrays esophageal motor function during food ingestion. Blonski et al. [4] demonstrated a number of differences on esophageal manometry between water and viscous material swallows-i.e. higher contraction amplitude $10 \mathrm{~cm}$ above the LES, slower distal onset velocities, and higher residual LES pressures with viscous swallowsin healthy volunteers. In addition, many patients with dysphagia have normal standard manometry. Furthermore, water swallows rarely reproduce the dysphagia experienced with more viscous or solid materials. This suggests that water swallows may not always be the optimum material for patients with dysphagia to swallow during esophageal manometry.

In this study, we tested the hypothesis that challenging patients complaining of dysphagia with more viscous (apple sauce) swallows during high-resolution esophageal manometry uncovers abnormalities of esophageal motor function that are not seen during standard water swallows.

\section{Methods}

Subjects

Consecutive patients presenting to a tertiary care medical center from January 1, 2006 to June 1, 2008 with dysphagia as the primary reason for high-resolution esophageal manometry (HRM) were eligible for inclusion in the study. Subjects were eligible if the HRM did not provide a diagnostic explanation for the dysphagia with water swallows alone. Subjects were excluded if they demonstrated simultaneous esophageal pressure waves with $\geq 2(20 \%)$ of 10 wet swallows or $\geq 3$ (30\%) of the swallows produced hypotensive peristaltic events (see definition below). After exclusion criteria were met, subjects were given an additional 10 swallows with a viscous material $(3 \mathrm{ml}$ apple sauce). Available data from endoscopies, biopsies, 24-h esophageal $\mathrm{pH}$ testing, and progress notes (i.e. type of dysphagia, history of gastroesophageal reflux or chest pain) was recorded. This study was approved by the institutional review board.

\section{High-Resolution Manometry}

All subjects presented to the GI Motility Laboratory for HRM after a minimum $8 \mathrm{~h}$ fast. Medications known to inhibit or affect esophageal motility were discontinued 5 days before HRM. A solid-state manometry catheter with 36 circumferential pressure transducers (Sierra Scientific Instruments; Los Angeles, CA, USA) spaced at 1-cm intervals on the center was used for the manometry. A Manoshield (Sierra Scientific Instruments) was threaded over the catheter for sanitary protection. The catheter was calibrated from 0 to $300 \mathrm{mmHg}$ using externally applied pressure immediately before use. It was then inserted transnasally into the esophagus with distal channels located in the stomach, as identified by positive pressure deflection with deep inspiration. The catheter was then positioned to incorporate visualization of the upper (UES) and lower esophageal sphincter (LES) in the field of view. This enabled simultaneous recording of pressure from the hypopharynx to the proximal stomach. The high-resolution catheter was designed to sense pressure at twelve positions around its circumference, and the final pressure output was the average from these twelve positions.

Patients were placed in a $30^{\circ}$ semi-recumbent position and allowed to accommodate to the catheter. Once comfortable, a $30 \mathrm{~s}$ recording was made with the patient at rest and not swallowing. This was done to measure the resting LES and UES pressures. Immediately after resting pressure measurement, the subjects were given 5-ml room-temperature water swallows in a sequence of 10 swallows. After 
water swallows, subjects were given 10 viscous swallows using 3-ml apple sauce per swallow. Viscous swallows were administered through a syringe and patients were told to hold the material in their mouth until told to swallow. A smaller bolus volume was chosen for apple sauce to account for the differences in viscosity between apple sauce and water. Artifacts are uncommon in our experience of using viscous swallows. Both water and viscous swallows were given $30 \mathrm{~s}$ apart. Double swallows and swallows including pressure artifacts associated with coughing or belching were not counted in the 10 swallows.

\section{Data Analysis}

Manometric recordings of esophageal motor function were acquired with the Manoscan manometry system (Sierra Scientific Instruments). The mean resting UES and LES pressures were determined at the beginning of the study over a thirty-second period during which there were no swallows. A software algorithm that uses pressure data from the high-resolution manometry catheter to mimic the Dent sleeve measured the residual LES pressure automatically. This electronic sleeve (eSleeve; Sierra Scientific Instruments) reports the highest pressure between its proximal and distal boundaries at each instant in time. Residual LES pressure was determined by the 3-second nadir algorithm, which finds the continuous 3-s time interval during the swallow sequence that has the lowest mean pressure relative to gastric pressure. This is reported as residual LES pressure. Each swallow frame was reviewed manually to ensure proper positioning of measurement tools for evaluation of UES, esophageal, and LES function.

Pressure wave amplitude (normal, $30-180 \mathrm{mmHg}$ ) and velocity over the smooth muscle segment (normal $<8.0 \mathrm{~cm} / \mathrm{s}$ ) were determined automatically using the Manoscan analysis software. Velocity was determined from pressure sensors 3, 7, and $11 \mathrm{~cm}$ above the upper border of the LES. The transition zone for each swallow was manually measured using the SmartMouse tool (Sierra Scientific Instruments) of the Manoscan analysis software.

The transition zone [5] was defined as the distance $(\mathrm{cm})$ along the $\mathrm{y}$ axis from the most distal portion of the $40 \mathrm{mmHg}$ isobaric contour of the striated muscle esophagus contraction to the most proximal portion of the $40 \mathrm{mmHg}$ isobaric contour of the smooth muscle esophagus contraction in all non-failed swallows [6]. The $40 \mathrm{mmHg}$ isobaric contour (rather than a lower pressure) was chosen to avoid a lack of distinction between isobaric contour plots. The intra-bolus pressure represents pressure in the bolus that precedes the peristaltic contraction [7]. It was recorded manually for each swallow as the pressure just before the rapid upstroke of the peristaltic pressure wave. The rapid upstroke corresponds to closure of the esophageal lumen by the peristaltic contraction [8]. Each set of swallows was assessed for repetitive pressure waves characterized by cyclical variations in esophageal pressure.

Each swallow was categorized as normal, hypotensive, or simultaneous. To be judged normal, swallow-induced peristaltic pressure contours had to be $\geq 30 \mathrm{mmHg}$ and span a length of $\geq 5 \mathrm{~cm}$ in the distal esophagus, ending at the LES. Swallows generating distal contours $\geq 30 \mathrm{mmHg}$ contour plots over $<5 \mathrm{~cm}$ were considered hypotensive. Simultaneous pressure waves were defined as swallowinduced pressure contours that propagated over the smooth muscle segment at a rate exceeding $8.0 \mathrm{~cm} / \mathrm{s}$.

Subjects were identified as having ineffective esophageal motility (IEM) when $\geq 30 \%$ swallow-induced pressure waves were hypotensive. Pressurization was diagnosed when $\geq 20 \%$ of pressure contours were simultaneous in the distal esophagus, and some swallows produced normal peristalsis. In general, abnormality was defined as IEM, DES, or both.

\section{Statistical Analysis}

To compare the prevalence of abnormal motor function before and after viscous swallows a chi-squared test was used. To determine if any abnormal water swallow during the study predicted abnormal viscous swallows, a McNemar's test was used. Comparisons of continuous data during water and viscous apple sauce swallows were made by use of a paired $t$ test. A $P$-value of $<0.05$ was considered significant and continuous data were expressed as a mean \pm standard error of mean (SEM).

\section{Results}

\section{Subjects}

High-resolution manometry studies of 41 consecutive subjects presenting for evaluation of dysphagia were analyzed. The average age of patients included in the study was $53.6 \pm 2.5$ (range 14-80) years. Fifteen (36.6\%) were males and $26(63.4 \%)$ females. Gastroesophageal reflux disease (GERD) and chest pain were reported in 76.9 and $51.9 \%$ of patients with available clinical data, respectively. Neither was significantly associated with any of the motility data assessed. In the 10 patients in whom the type of dysphagia was specified, seven had dysphagia with solids only and three with both solids and liquids. The mean basal UES and LES pressures were $73.3 \pm 5.3$ and $12.1 \pm 1.4 \mathrm{mmHg}$, respectively. Hypotensive UES and LES were observed in 12.1 and $41.5 \%$ of the study population, respectively. 
Upper endoscopy reports were available for 17 of the 41 patients. Endoscopic findings included hiatal hernia $(n=6)$, antral erythema $(n=4)$, gastritis $(n=4)$, narrowing of the distal esophagus $(n=3)$, and esophageal rings $(n=3)$. Esophageal erythema $(n=2)$, furrows $(n=1)$, and cricopharyngeal bar $(n=1)$ were uncommon. The only abnormality commonly reported on biopsies was mild chronic gastritis $(n=11)$. Sleuth 24-h intraesophageal impedence $\mathrm{pH}$ and 24-h esophageal $\mathrm{pH}$ test results were available for five and eight patients, respectively. In the former group, increased acid exposure $(\mathrm{pH}<4)$ was present in $4.0 \pm 3.1 \%$ of total study time, mean DeMeester score was $19.7 \pm 3.1$, mean bolus clearance time was $17.3 \pm 3.9 \mathrm{~s}$ (normal $<44 \mathrm{~s}$ ), and mean total reflux episodes was $34.1 \pm 23.6$ (normal <73). Increased distal $(>5 \%)$ and proximal $(>1 \%)$ acid exposure were each observed in four patients with $24-\mathrm{h}$ esophageal $\mathrm{pH}$ testing.

\section{Esophageal Motor Activity}

Among 41 subjects, 408 recorded water swallows were performed. Of these, $393(96.3 \%)$ produced normal peristalsis, $12(2.9 \%)$ were hypotensive, and three $(0.7 \%)$ were simultaneous (Fig. 1). When apple sauce was administered, 354 swallows were available for analysis. Of these, 249 $(70.3 \%)$ were normal, $59(16.7 \%)$ were hypotensive, and $46(13.0 \%)$ were simultaneous. Each of these categories differed statistically from water swallows (Fig. 1).

\section{IEM and Pressurization Labeling in Subjects}

None of the subjects, by definition, met our criteria for diagnosing ineffective esophageal motility disorder or pressurization when water swallows were given. With

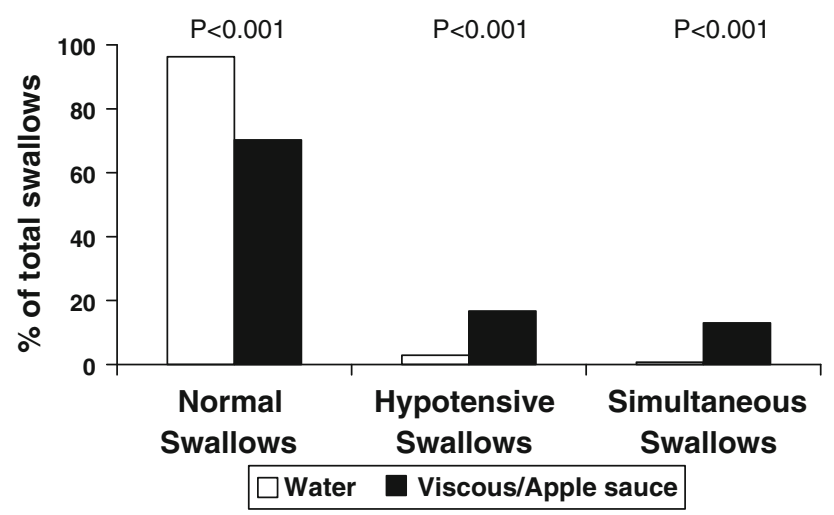

Fig. 1 Comparison of abnormalities in esophageal contractions with water and viscous swallows. The differences for each category were statistically significant for water swallows compared to viscous swallows. Comparison between groups was made by use of a chisquared test apple sauce swallows seven subjects $(17.1 \%)$ met the criteria for IEM; these subjects had a higher mean proportion of hypotensive swallows with apple sauce $(53.7 \pm 8.1 \%)$ compared with water swallows $(3.7 \pm 2.6 \%)(P<0.001)$. Nine subjects $(22.0 \%)$ met criteria for pressurization; mean number of simultaneous swallows was higher with apple sauce $(42.5 \pm 5.6 \%)$ than water swallows $(3.9 \pm 1.1 \%)$ $(P<0.001)$. Overall, 14 subjects $(34.1 \%)$ were given an alternative diagnosis of pressurization or IEM based on abnormal viscous apple sauce swallows (two subjects had both DES and IEM). Hypotensive UES or LES did not predict IEM or pressurization.

\section{Correlation in Swallow Outcomes Between Water} and Viscous Boluses

Three comparisons were made to examine whether subclinical findings with water swallows were predictive of findings with viscous apple sauce swallows. The first was to determine whether any hypotensive or simultaneous pressure contours produced by wet swallows predicted any hypotensive or simultaneous contours using apple sauce. Using McNemar's test, any abnormal wet swallows predicted the same with apple sauce swallows (OR $=9.00$, $\mathrm{CI}=2.15-80.0)$. However, any subdiagnostic $(<20 \%)$ simultaneous pressure contours with water swallows did not predict pressurization during apple sauce swallows ( $\mathrm{OR}=7.00, \mathrm{CI}=0.90-315.4)$. Furthermore, the presence of any hypotensive swallow with water was not predictive of true IEM when apple sauce swallows were used $(\mathrm{OR}=0.63, \mathrm{CI}=0.16-2.17)$. In regard to overt abnormalities with water swallows, an abnormal proportion of double-peaked waves $(>20 \%)$ with water swallows predicted the same with apple sauce swallows (OR $=4.33$, $\mathrm{CI}=1.19-23.71)$, but the same was not true of evaluation of abnormal proportion of triple-peaked waves (1.40, $\mathrm{CI}=0.38-5.59)$.

\section{Other Manometric Measures}

Of the other manometric data measured and compared with water and apple sauce swallows, a number of outcomes were not different (Table 1). In particular, UES and LES residual pressures and the frequency of relaxation errors were similar. However, pressure wave velocity was more rapid and intra-bolus pressure was higher with apple sauce swallows. Furthermore, the mean proportion of doublepeaked waves was higher with apple sauce swallows $(27.1 \pm 3.9 \%)$ than with water swallows $(17.9 \pm 3.3 \%)$ $(P=0.021)$, and more patients had an abnormal proportion $(>20 \%)$ of double-peaked waves with apple sauce $(59 \%)$ than with water swallows $(36 \%)(P=0.010)$, whereas the occurrence of triple-peaked waves was similar 
Table 1 Comparisons between water and viscous apple sauce swallows

\begin{tabular}{lrrr}
\hline & \multicolumn{1}{l}{ Water } & $\begin{array}{l}\text { Viscous/ } \\
\text { apple sauce } \\
\end{array}$ & Mean (SE) \\
& Mean (SE) & \\
\hline Velocity (cm/s) & $3.0(0.1)$ & $5.6(1.1)$ & 0.014 \\
Amplitude (mmHg) & $90.9(6.5)$ & $84.4(6.1)$ & 0.113 \\
Intra-bolus pressure (mmHg) & $15.2(0.8)$ & $20.5(0.9)$ & $<0.001$ \\
Transition zone (cm) & $4.2(0.3)$ & $4.4(0.4)$ & 0.682 \\
UES residual (mmHg) & $5.1(0.6)$ & $4.8(0.8)$ & 0.732 \\
LES residual $(\mathrm{mmHg})$ & $7.2(0.8)$ & $8.1(0.7)$ & 0.080 \\
\hline
\end{tabular}

Comparison between groups was by paired $t$ test

SE, standard error; UES residual, upper esophageal sphincter residual pressure; LES residual, lower esophageal sphincter residual pressure

in viscous $(7.7 \pm 2.0 \%)$ and water swallows $(5.1 \pm 2.3 \%)$ $(P=0.427)$.

\section{Discussion}

The current testing environment of HRM, using water swallows, does not simulate the demands on esophageal function presented during a regular meal, and seldom reproduces the symptom of dysphagia. To determine if a viscous material increases the diagnostic value of HRM, we gave apple sauce swallows to patients with dysphagia after normal HRM using water swallows. Approximately onethird of apple sauce swallows produced esophageal motor abnormalities. The presence of any abnormal water swallows predicted abnormal pressure waves with apple sauce swallows, suggesting that esophageal motor dysfunction occurring with water swallows might predict a classifiable motor abnormality produced by apple sauce swallows. However, a hypotensive peristaltic pressure contour or simultaneous pressure wave produced by water swallows did not predict IEM or pressurization with apple sauce swallows, although this may have been affected by the small number of total hypotensive and simultaneous water swallows. Nonetheless, our prominent abnormal viscous swallow findings support an adjunctive role that may:

1 help divulge subclinical pathology not detected in patients with relatively normal water swallow in HRM studies;

2 indicate the need for further evaluation of dysphagia in these patients; and

3 identify specific food consistencies that are poorly tolerated and should therefore be avoided.

Apple sauce is a novel medium for testing esophageal manometry, and therefore a paucity of normative data exists. We selected this medium because it provides a known and normalized consistency that can be assessed in an evaluation of multiple patients such as in our study. Although this may not completely emulate a regular daily diet, we believe that clearing of the bolus in a single swallow enables better portrayal of deglutination physiology and anatomy. Our bolus material is also similar in consistency to one used in other investigative studies (Sandhill Scientific, Littleton, CO, USA). Tutuian et al. [9] evaluated a viscous material with "apple sauce-like consistency" in 43 normal subjects using combined multichannel intraluminal impedence and manometry (MII-EM) and reported a similar number of normal, ineffective, and simultaneous swallows compared with water swallows. A subsequent study reported similar duration and mean amplitude of contractions [10]. Compared with water swallows, marshmallow swallows produce fewer abnormal contractions in normal adults and more abnormal contractions in subjects with dysphagia [11].

Although bolus transport time and contraction wave velocity are similar with different water volumes, these outcomes are positively and inversely correlated, respectively, with increasing apple sauce bolus volume [12]. To help accommodate these differences, which are likely to be associated with disparate viscosities, we chose a bolus volume for apple sauce $(3-\mathrm{ml})$ which was smaller than the traditional water bolus volume $(5-\mathrm{ml})$. We observed a mean velocity of peristaltic pressure waves with apple sauce swallows which was almost twice that seen with water swallows. This indicates a pathologic process-because reduced contraction velocity has been reported with semisolid boluses in healthy subjects [11] - and correlates clinically with the often described situation in which a patient may have more profound esophageal symptoms, i.e. dysphagia, with solids or semi-solids than with liquids [13].

In contrast with semisolid boluses, abnormal motility (i.e. peristaltic dysfunction, synchronous contractions, and non-conducted swallows) and symptoms with solid food (e.g. bread) ingestion have been reported in small studies [14-17]. Solid boluses, however, may not be cleared on a single swallow and affect manometric data on subsequent swallows. Unchewed bread is less readily cleared than chewed bread [18] and produces more slowly propagating, higher amplitude, and longer duration peristaltic pressure waves compared with water [11, 19, 20]. Contrastingly, we observed increased peristaltic velocity and a trend toward lower peristaltic amplitude with apple sauce. We also observed higher mean intra-bolus pressure with apple sauce than with water, suggesting the esophagus must work harder to transport the apple sauce. Bernhard et al. [17] previously noted a similar prevalence of motility abnormalities in patients with dysphagia, chest pain, and GERD during recumbent bread swallows, but more frequent abnormalities in patients with chest pain and GERD during 
upright bread swallows. We did not observe an increased prevalence of motor abnormalities in patients with chest pain or GERD.

HRM is a new technique for which normal results are still being defined. Our definitions for normal results are based mostly on criteria proposed by Spechler and Castell [21] for interpretation of conventional manometry. There is reasonable agreement that numerical quantification of conventional and high-resolution manometry data should be similar. A limitation of our study is the lack of normative data for apple sauce swallows. However, on the basis of previous studies reporting similar traditional manometry and MII-EM results in healthy volunteers [912], as discussed above, we believe it is prudent to use the same criteria for water and viscous swallows. Because this is a retrospective study at a tertiary care center in which a number of patients were referred for HRM by outside gastroenterologists, we did not have clinical data available for all patients. It would be helpful to quantify the severity of dysphagia with a questionnaire or visual analog scale before the procedure, and we are implementing such tools for better future characterization of our patients. Furthermore, some of the symptoms associated with the presence of GERD or chest pain may have reached clinical significance if a larger study population had been used.

In summary, identification of classifiable motor disorders is increased by using apple sauce as a viscous challenge when traditional water swallows fail to identify a motor abnormality in patients presenting with dysphagia. Apple sauce may challenge the esophagus in a way somewhat akin to other semi-solid materials. Given the low yield of pathologic findings with water swallows in patients presenting with dysphagia, this adjunct may potentially help make a previously unnoticed diagnosis or may aid in therapeutic decisions. Its clinical usefulness and the mechanisms by which it alters esophageal function, however, are yet to be evaluated in full, and further study is necessary to validate the utility and role of apple sauce boluses in HRM.

Conflict of interests Jeffrey L. Conklin is a consultant for Sierra Scientific Instruments. Guarantor of the article: Jeffrey L. Conklin, MD.

Open Access This article is distributed under the terms of the Creative Commons Attribution Noncommercial License which permits any noncommercial use, distribution, and reproduction in any medium, provided the original author(s) and source are credited.

\section{References}

1. Pandolfino JE, Kahrilas PJ. AGA technical review on the clinical use of esophageal manometry. Gastroenterology. 2005;128: 209-224.
2. Fox M, Hebbard GS, Janiak P, et al. High-resolution manometry predicts the success of oesophageal bolus transport and identifies clinically important abnormalities not detected by conventional manometry. Neurogastroenterol Motil. 2004;16:533-542.

3. Freeman J, Hila A, Castell DO. Esophageal manometry. In: Castell DO, Richter JE, eds. The esophagus. 4th ed. New York: Lippincott Williams \& Wilkins; 2004:115-134.

4. Blonski W, Vela M, Hila A, Castell DO. Normal values for manometry performed with swallows of viscous test material. Scand J Gastroenterol. 2008;43:155-160.

5. Ghosh SK, Janiak P, Schwizer W, et al. Physiology of the esophageal pressure transition zone: Separate contraction waves above and below. Am J Physiol Gastrointest Liver Physiol. 2006;290:G568-G576.

6. Ghosh SK, Pandolfino JE, Zhang Q, et al. Quantifying esophageal peristalsis with high-resolution manometry: A study of 75 asymptomatic volunteers. Am J Physiol Gastrointest Liver Physiol. 2006;290:G988-G997.

7. Murray JA, Clouse RE, Conklin JL. Components of the standard oesophageal manometry. Neurogastroenterol Motil. 2003;15: 591-606.

8. Kahrilas PJ, Dodds WJ, Hogan WJ. The effect of peristaltic dysfunction on esophageal volume clearance. Gastroenterology. 1988;94:73-80.

9. Tutuian R, Vela MF, Balaji NS, et al. Esophageal function testing with combined multichannel intraluminal impedence and manometry: multicenter study in healthy volunteers. Clin Gastroenterol Hepatol. 2003;1:174-182.

10. Blonski W, Hila A, Jain V, Freeman J, Vela M, Castell DO. Impedance manometry with viscous test solution increases detection of esophageal function defects compared to liquid swallows. Scand J Gastroenterol. 2007;42:917-922.

11. Keren S, Argaman E, Golan M. Solid swallowing versus water swallowing: Manometric study of dysphagia. Dig Dis Sci. 1992; 37:603-608.

12. Srinivasan R, Vela MF, Katz PO, Tutuian R, Castell JA, Castell DO. Esophageal function testing using multichannel intraluminal impedance. Am J Physiol Gastrointest Liver Physiol. 2001;280: G457-G462.

13. Allen ML, Orr WC, Mellow MH, Robinson MG. Water swallows versus food ingestion as manometric tests for esophageal dysfunction. Gastroenterology. 1988;95:831-833.

14. Mellow MH. Esophageal motility during food ingestion: A physiologic test of esophageal motor function. Gastroenterology. 1983;85:570-577.

15. Howard PJ, Maher L, Pryde A, Heading RC. Systematic comparison of conventional oesophageal manometry with oesophageal motility while eating bread. Gut. 1991;32:1264-1269.

16. Holloway RH, Tippett MD, Horowitz M, Maddox AF, Moten J, Russo A. Relationship between esophageal motility and transit in patients with type I diabetes mellitus. Am J Gastroenterol. 1999;94:3150-3157.

17. Bernhard A, Pohl D, Fried M, Castell DO, Tutuian R. Influence of bolus consistency and position on esophageal high-resolution manometry findings. Dig Dis Sci. 2008;53:1198-1205.

18. Pouderoux P, Shi G, Tatum RP, Kahrilas PJ. Esophageal solid bolus transit: studies using concurrent videofluoroscopy and manometry. Am J Gastroenterol. 1999;94:1457-1463.

19. Johnston BT, Collins JS, McFarland RJ, Blackwell JN, Love AH. A comparison of esophageal motility in response to bread swallows and water swallows. Am J Gastroenterol. 1993;88:351-355.

20. Dooley CP, Di Lorenzo C, Valenzuela JE. Esophageal function in humans. Effect of bolus consistency and temperature. Dig Dis Sci. 1990;35:167-172.

21. Spechler SJ, Castell DO. Classification of oesophageal motility abnormalities. Gut. 2001;49:145-151. 